This item was submitted to Loughborough's Research Repository by the author.

Items in Figshare are protected by copyright, with all rights reserved, unless otherwise indicated.

\title{
Optimum design and testing of a postbuckled stiffened panel
}

\section{PLEASE CITE THE PUBLISHED VERSION}

http://www.aiaa.org/content.cfm?pageid=2

\section{PUBLISHER}

(c) American Institute of Aeronautics and Astronautics (AIAA)

\section{VERSION}

AM (Accepted Manuscript)

\section{LICENCE}

CC BY-NC-ND 4.0

\section{REPOSITORY RECORD}

Lillico, M., R. Butler, G.W. Hunt, Andrew Watson, David Kennedy, and F.W. Williams. 2011. "Optimum Design and Testing of a Postbuckled Stiffened Panel”. figshare. https://hdl.handle.net/2134/8677. 
This item was submitted to Loughborough's Institutional Repository (https://dspace.lboro.ac.uk/) by the author and is made available under the following Creative Commons Licence conditions.

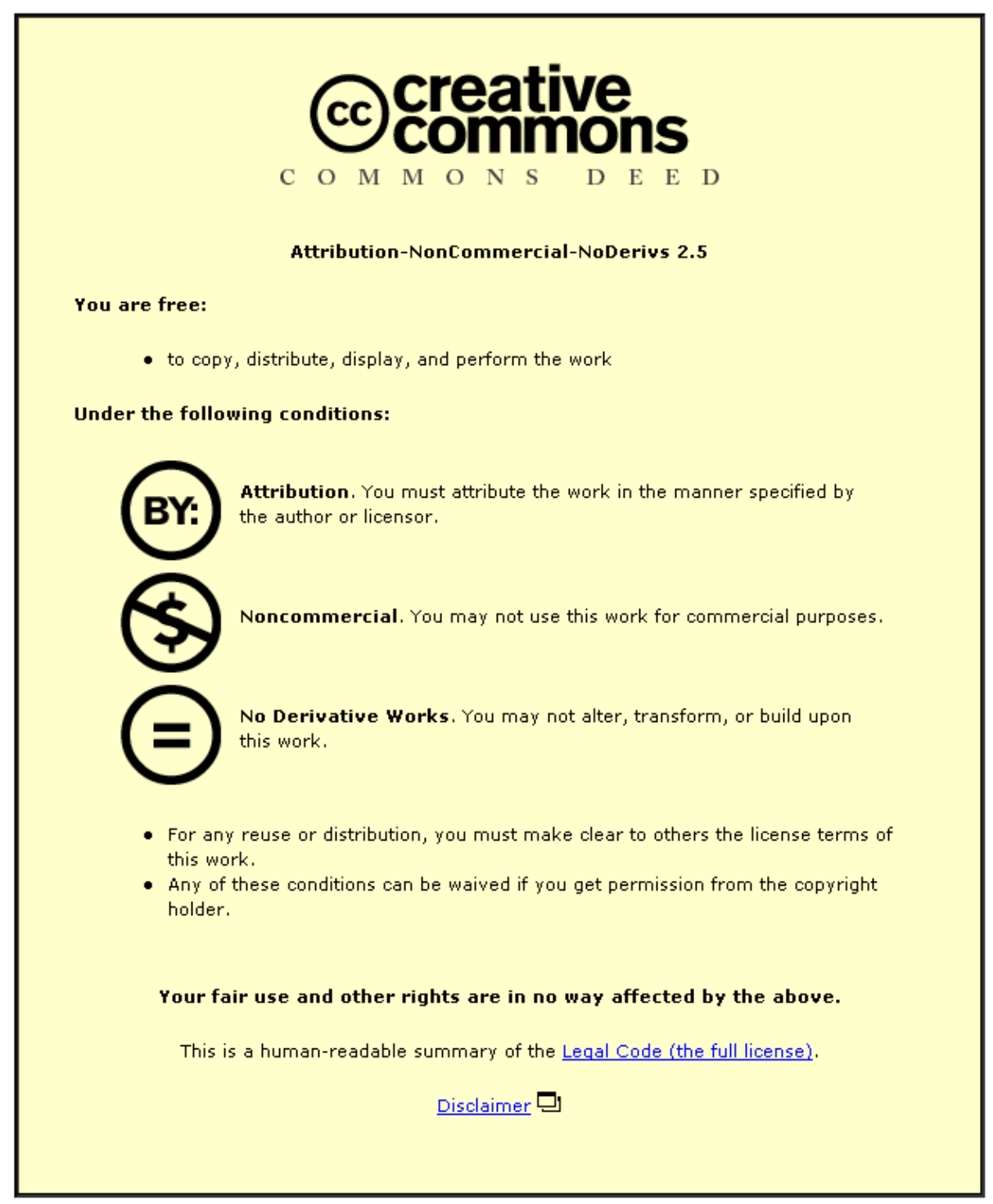

For the full text of this licence, please go to: http://creativecommons.org/licenses/by-nc-nd/2.5/ 


\title{
OPTIMUM DESIGN AND TESTING OF A POST-BUCKLED STIFFENED PANEL
}

\author{
M. Lillico*, R. Butler ${ }^{\dagger}$ and G.W. Hunt ${ }^{*}$ \\ Department of Mechanical Engineering, University of Bath, United Kingdom, BA2 7AY. \\ A. Watson ${ }^{\S}$, D. Kennedy ${ }^{\text {Il }}$ and F.W. Williams ${ }^{\#}$ \\ Cardiff School of Engineering, Cardiff University, United Kingdom, CF24 3TB.
}

\begin{abstract}
The efficient, industrially used, linear elastic preliminary design software VICONOPT is employed to design a stiffened panel with a post-buckled reserve of strength. The initial buckling mode is a local skin mode in longitudinal compression with allowance being made for the effects of an initial overall imperfection. The resulting panel has been analyzed using the non-linear FE package ABAQUS and four laboratory specimens have been tested to failure. The similarity of the experimental failure with the VICONOPT and ABAQUS predictions suggests that VICONOPT can give a satisfactory preliminary design. While neither model matches completely the boundary conditions found in a real aircraft compression panel, it is suggested that the VICONOPT model may be a better representation than either the ABAQUS model or the experimental tests.
\end{abstract}

\section{Introduction}

It is well known that stiffened panels, used extensively within the aerospace industry, can have a considerable post-buckling reserve of strength, enabling them to remain in stable equilibrium under loads in excess of their critical buckling load when the initial buckling mode is local, but not if it is an overall or Euler mode.

There is an extensive literature on the postbuckling $^{1}$ of plates, covering empirical work, experiments and analytic solutions including finite element and finite strip methods. Optimum design techniques have been developed to produce minimum mass designs for a given loading which allow for post-buckling strength ${ }^{2,3}$ and may even consider the possibility of mode jumping.

In the design of aerospace structures, great emphasis is placed on mass minimization in order to reduce life-cycle costs. An optimum design procedure based on initial buckling, stress or strain, and stiffness

\footnotetext{
* Research Assistant

$\uparrow$ Senior Lecturer in Aerospace Structures

Professor of Structural Mechanics

$\S$ Research Associate

II Lecturer, Member AIAA

\# Professor of Structural Engineering

Copyright $@$ 2000. The American Institute of Aeronautics and

Astronautics Inc. All rights reserved.
}

constraints typically results in an idealized structural configuration which has almost equal critical loads for local and overall buckling. This is likely to be highly unstable in the post-buckling region owning to mode interaction, in which the overall bending stiffness is reduced by local post-buckling deformations possibly leading to sudden failure of the structure. ${ }^{6}$

In this paper the industrially used linear elastic software VICONOPT $^{7}$ is employed to design a stiffened panel with a post-buckling reserve of strength. This code involves some postbuckling approximations ${ }^{3}$ which cannot be used in analysis but which drastically reduce the computations involved so as to give an acceptable preliminary design tool. The initial buckling mode is a local skin mode in longitudinal compression and the panel is loaded beyond initial buckling to failure, allowance being made for the effects of an initial overall imperfection. The VICONOPT design allows for the redistribution of stress at buckling, so that local buckling can occur in the inter-stiffener portions of the skin at loads less than the design load. This redistribution is achieved by using an assumed ratio $\alpha$ of post-buckled to prebuckled stiffnesses for such portions, which applies only when the total load on the panel exceeds an assumed fraction $\beta$ of the (ultimate) design load, $\mathrm{P}_{\mathrm{d}}$.

The resulting panel has been analyzed using the finite element package $\mathrm{ABAQUS}^{8}$ and four test specimens have been fabricated and tested experimentally. The present paper compares the VICONOPT, ABAQUS and experimental results, and thereby assesses the suitability of VICONOPT for designing a panel with post-buckling reserve of strength.

\section{Theoretical Background to VICONOPT}

VICONOPT $^{7}$ (VIPASA with CONstraints and OPTimisation) is a FORTRAN 77 computer program that incorporates the earlier programs VIPASA (Vibration and Instability of Plate Assemblies including Shear and Anisotropy) and VICON (VIPASA with CONstraints). It covers any prismatic plate assembly, i.e., panels of constant cross section, composed of anisotropic plates each of which can carry any combination of uniformly distributed and longitudinally invariant in-plane stresses. It can be 
used as either an analysis or an optimum design program. The analysis principally covers the calculation of eigenvalues, i.e., the critical load factors in elastic buckling problems or the natural frequencies in undamped vibration problems. The analysis is based on the exact solution of the governing differential equations of the constituent members, which are assumed to undergo a deformation that varies sinusoidally to infinity in the longitudinal direction, yielding exact stiffness matrices whose elements are transcendental functions of the load factor or frequency and the axial halfwavelength, $\lambda$, of the deformation. The resulting transcendental eigenproblem requires an iterative solution which is performed using the WittrickWilliams algorithm. ${ }^{9}$ The simplest form of the buckling analysis ${ }^{10,11}$ is performed over a range of values of $\lambda$ that usually extends from a value less than the smallest plate width to the length, $l$, of the panel. The lowest buckling load found for any $\lambda$ is taken as the critical buckling load for the panel. This implies that the panel of length $l$ is simply supported at its ends with warping of the entire cross-section allowed.

For panels designed to have post-buckling strength, two modifications were $\operatorname{made}^{3}$ to the basic method of VICONOPT. These and the original VICONOPT options are too extensive to quote in detail, so only the features and options needed to understand the current paper are given here. The first modification was the introduction of the parameters $\alpha$ and $\beta$ described above. In this paper $\alpha=0.5$ was applied to the three skin portions of width $b_{u}$ shown on Fig. 1, i.e., the skin portions between adjacent bonded stiffener flanges, which were assumed to buckle locally at $\beta=0.6$ times the design load. Hence the stresses due to compression alone are such that the longitudinal strain is the same for all plates and the reduced buckled plate stiffnesses defined by $\alpha=0.5$ are used only after the axial force $\mathrm{P}$ exceeds $\beta \mathrm{P}_{\mathrm{d}}$. Other values of $\alpha$ and $\beta$ could have been used based either on judgement or on a preliminary local postbuckling analysis, e.g., using an extra analysis option of VICONOPT. ${ }^{12}$ The second modification was to perform approximate calculations to allow for an initial longitudinally sinusoidal overall imperfection of amplitude $\delta_{0}$. By treating the entire cross-section of Fig. 1 as that of a wide strut, with $\alpha=0.5$ used for the appropriate plates, the buckling load was calculated using the Euler formula $\mathrm{P}_{\mathrm{E}}=\pi^{2} \mathrm{EI} / l^{2}$. Then, for local buckling, the stress distribution over the cross-section due to compression alone was modified by the action of a bending moment

$$
\mathrm{M}_{\mathrm{d}}=\frac{\mathrm{P}_{\mathrm{d}} \delta_{\mathrm{o}}}{1-\mathrm{P}_{\mathrm{d}} / \mathrm{P}_{\mathrm{E}}}
$$

where the denominator allows for the amplification of the initial mid-length imperfection $\delta_{\mathrm{o}}$ caused by $\mathrm{P}_{\mathrm{d}}$.
The VICONOPT optimization procedure ${ }^{7}$ consists of cycles in each of which, constraints, sensitivities and move limits are calculated and used in a linear optimization step, which is ideally followed by a stabilization step. The linear optimizer gives designs which are only approximate because the information it receives is linearized at the design configuration at which the cycle starts, whereas the true optimization problem is non-linear. The stabilization step makes the design just stable by scaling all the design variable thicknesses that are not restricted by bounds, but has to be omitted when, as in this paper, the restriction to available gauge thicknesses prevents the thicknesses from being scaled. The effect of modifying the stress distribution to allow for $\alpha, \beta$ and $\delta_{o}$ in the calculations of each design cycle and computing for the individual $\lambda$ values given by $\lambda=l / i(\mathrm{i}=2,3, .$.$) is to$ produce a design for which buckling first occurs for the modified stress distribution at some load approximately equal to $\mathrm{P}_{\mathrm{d}}$ which is taken as being the failure load. (Where initial local skin buckling loads are quoted in this paper they were calculated with $\alpha=1$ and hence, because isotropic material was used, this gives uniform stress over the panel cross-section. The $\alpha=0.5$ calculations give a higher buckling load because the skin stress is much lower than the stiffener stress.)

\subsection{Design Constraints}

3.VICONOPT Panel Design

The objective was a minimum mass design of the panel indicated in Fig. 1 with free longitudinal edges, subject to sets of buckling, material strength and practical constraints. Aluminum 6082-T6 was used to fabricate the panels, with elastic modulus $\mathrm{E}=72.4 \mathrm{GPa}$, Poisson's ratio $v=0.33$, density $\rho=2800 \mathrm{~kg} / \mathrm{m}^{3}$ and the $0.2 \%$ proof stress $=283 \mathrm{MPa}$. The practical constraints fell into the three categories of testing rig constraints, panel dimension constraints and the discrete material thicknesses available. The testing rig limited the overall panel width to be less than $300 \mathrm{~mm}$ and the failure load to be less than $100 \mathrm{kN}$. The minimum and

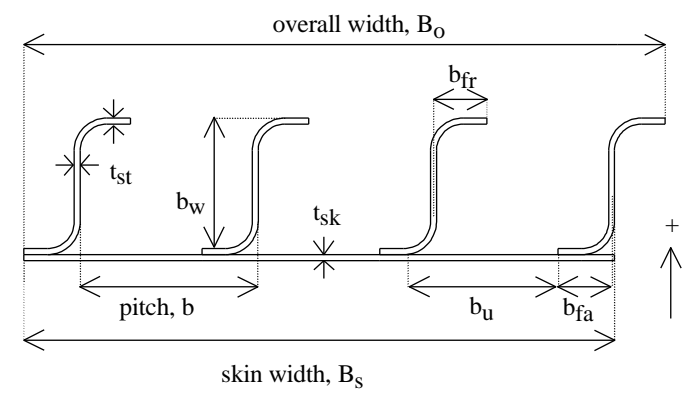

Fig. 1. Cross section of the panel showing $b_{u}$, the six design variables of an unconstrained design and the direction taken as positive for the imperfection. The panel length was $539 \mathrm{~mm}$ and the material was Al6082-T6. 
Table 1 Comparison of the designs, with and without practical constraints.

\begin{tabular}{c|ccccc}
\hline \hline Variable & Constraint & \multicolumn{2}{c}{ Constrained } & \multicolumn{2}{c}{ Unconstrained } \\
& value & Start & End & Start & End \\
\hline $\mathrm{b}_{\mathrm{fr}}, \mathrm{mm}$ & $\geq 10$ & 10.0 & 10.0 & 10.0 & 10.9 \\
$\mathrm{~b}_{\mathrm{w}}, \mathrm{mm}$ & $28 \leq \mathrm{b}_{\mathrm{w}} \leq 65$ & 28.0 & 28.0 & 28.0 & 25.4 \\
$\mathrm{~b}_{\mathrm{fa}}, \mathrm{mm}$ & $\geq 10$ & 10.0 & 18.5 & 10.0 & 9.1 \\
$\mathrm{~b}, \mathrm{~mm}$ & - & 74.5 & 79.2 & 74.5 & 65.1 \\
$\mathrm{t}_{\mathrm{st}}, \mathrm{mm}$ & $=1.2$ & 1.2 & 1.2 & 1.42 & 1.53 \\
$\mathrm{t}_{\mathrm{sk}}, \mathrm{mm}$ & $=1.0$ & 1.0 & 1.0 & 1.10 & 1.07 \\
$\gamma=\mathrm{A}_{\mathrm{s}} / \mathrm{bt}$ & $0.75 \leq \gamma \leq 0.8$ & 0.73 & 0.82 & 0.79 & 0.94 \\
$\mathrm{~B}_{\mathrm{s}}, \mathrm{mm}$ & - & 234.1 & 256.6 & 234.2 & 205.1 \\
$\mathrm{~B}_{\mathrm{o}}, \mathrm{mm}$ & $\leq 300$ & 243.5 & 266.0 & 243.5 & 215.3 \\
\hline $\mathrm{Mass}_{\mathrm{ma}}$ & - & 0.682 & 0.778 & 0.778 & 0.727 \\
\hline \hline
\end{tabular}

maximum permitted total depths of the panel in $\mathrm{mm}$ were such that $28 \leq b_{w} \leq 65$. The grips used when bending to form the upper and lower stiffener flanges required them to be at least $10 \mathrm{~mm}$ wide, i.e., $\mathrm{b}_{\mathrm{fr}} \geq 10 \mathrm{~mm}$. The relevant material thicknesses available from the suppliers were $0.7,1.0,1.2$ and $1.5 \mathrm{~mm}$. An additional constraint often considered in industry governs $\mathrm{A}_{\mathrm{s}} / \mathrm{bt}_{\mathrm{sk}}$, where $\mathrm{A}_{\mathrm{s}}$ and $\mathrm{bt}_{\mathrm{sk}}$ are the areas of, respectively, the stiffener and its associated skin. Therefore the constraint $0.75 \leq \mathrm{A}_{\mathrm{s}} / \mathrm{bt}_{\mathrm{sk}} \leq 0.80$ was adopted.

On the basis of numerous preliminary results, including the unconstrained design results given in the final column of Table 1 and some ABAQUS runs, it was decided that the various practical constraints would be met efficiently by using a panel of length $l=539 \mathrm{~mm}$ with a compressive design load of $69 \mathrm{kN}$ applied at its neutral axis and with a maximum allowable mid-surface strain (to at least stay close to the VICONOPT elastic assumptions) of 3600 microstrain ( $\mu$ strain) in any plate. The design variables, shown in Fig. 1, were the widths of the two flanges of the stiffener, $b_{f a}$ and $b_{f r}$, the web height, $b_{w}$ and the stiffener pitch, b. For the panel without practical constraints, the thicknesses of the stiffener, $\mathrm{t}_{\mathrm{st}}$, and skin, $\mathrm{t}_{\mathrm{sk}}$, were also included as design variables. The panel designs allowed for both positive and negative imperfections, $\delta_{o}$, of magnitude $l / 500$ and the inter-stiffener portions of skin were designated to initially buckle at $\beta=0.6$ times the design load (i.e., at $41.4 \mathrm{kN}$ ) with a post-buckled to pre-buckled stiffness ratio of $\alpha=0.5$.
Table 2. First three skin bifurcation buckling loads in $\mathrm{kN}$ (and associated half-wavelengths), for perfect panel.

\begin{tabular}{cccc}
\hline $\begin{array}{c}\text { Software: } \\
\text { (Model:) }\end{array}$ & VICONOPT & $\begin{array}{c}\text { ABAQUS } \\
\text { (V'OPT) }\end{array}$ & $\begin{array}{c}\text { ABAQUS } \\
\text { (expt) }\end{array}$ \\
\hline 1 & $46.6(l / 10)$ & $45.9(l / 9)$ & $43.8(l / 9)$ \\
2 & $46.9(l / 9)$ & $46.1(l / 8)$ & $44.0(l / 8)$ \\
3 & $47.1(l / 11)$ & $46.3(l / 10)$ & $44.3(l / 10)$ \\
\hline \hline
\end{tabular}

Simply supported ends were assumed and offsets ${ }^{10}$ between the centerlines of connected plates were taken into account in the computer model. As can be seen in Fig. 1, the flanges at either end of the stiffener include curved portions. These were modeled using VICONOPT and had a centerline radius of $3 \mathrm{~mm}$. The lower flange and the associated skin to which it is attached were modeled as a single plate, i.e., the adhesive used in the laboratory tests was assumed to ensure continuity between the two surfaces. Note that when calculating the $\mathrm{A}_{\mathrm{s}} / \mathrm{bt}_{\mathrm{sk}}$ ratio, the flange is made up of a skin portion and a stiffener portion. However both of these were assigned their full stiffness properties during design, i.e., $\alpha$ was applied only to the rest of the inter-stiffener skin portion. The small portion of skin to the right of the right-hand stiffener was also assumed to have full stiffness properties and its right hand edge is flush with the outside surface of the stiffener web above it.

\subsection{Test Panel Design Results}

Table 1 compares the designs with and without practical constraints. The mass penalty for attempting

Table 3. Initial buckling loads (and associated half-wavelength) and failure loads using post-buckling analyses. * indicates a solution taken from the load-end shortening plot.

\begin{tabular}{c|cccc}
\hline \hline Imperfection & $\begin{array}{r}\text { Software: } \\
(\text { Model: })\end{array}$ & VICONOPT & $\begin{array}{r}\text { ABAQUS } \\
\left(\mathrm{V}^{\prime} \mathrm{OPT}\right)\end{array}$ & $\begin{array}{c}\text { ABAQUS } \\
(\mathrm{expt})\end{array}$ \\
\hline \multirow{2}{*}{0} & Local buckling load, $\mathrm{kN}$ & $46.6(l / 10)$ & $43.7 \pm 0.4(l / 9)$ & $40.8 \pm 0.4(l / 9)$ \\
& Failure load, kN & - & $>87.2$ & 70.8 \\
\hline$-l / 500$ & Local buckling load, $\mathrm{kN}$ & $52.5(l / 10)$ & $48.0(l / 9) *$ & $45.9(l / 9)^{*}$ \\
& Failure load, kN & $>71.3(l / 2)$ & $>94.7$ & 78.8 \\
\hline$+l / 500$ & Local buckling load, kN & $42.4(l / 10)$ & $40.3 \pm 0.4(l / 9)$ & $39.1 \pm 0.2(l / 9)$ \\
& Failure load, $\mathrm{kN}$ & $>68.3(l / 9)$ & $>83.0$ & 65.4 \\
\hline \hline
\end{tabular}


to satisfy the constraints is $7.0 \%$. The first three initial buckling loads for the constrained design analyzed by VICONOPT with no imperfection are given in the second column of Table 2, and the loads and modes at initial buckling of the imperfect panels are given in the third column of Table 3, which also shows the VICONOPT minimum failure load predictions for both positive and negative imperfections. For the positive imperfection the minimum failure load is $68.3 \mathrm{kN}$, which is very close to the design load of $69 \mathrm{kN}$, whereas for the negative imperfection the minimum failure load is above the design load, i.e., the panel is stable at the design load. Table 3 shows the failure load half-wavelength was $l / 9$ for the positive imperfection case, which increases compressive load in the skin, and $l / 2$ for the negative imperfection case, which increases compressive load in the stiffener. Hence for the negative imperfection a torsional (stiffener) mode is critical, whereas for a positive imperfection a skin mode is critical. The torsional mode has a critical half-wavelength of $l / 2=269.5 \mathrm{~mm}$ which approximates the skin width of $256.6 \mathrm{~mm}$. For the skin mode the critical halfwavelength is $l / 9=59.9 \mathrm{~mm}$, i.e., it is approximately equal to the width $63.5 \mathrm{~mm}$ of the inter stiffener portion of skin.

The peak strains at the design load are given in the second column of Table 4. The peak strains occurred in the skin for the positive imperfection case and in the flange remote from the skin for the negative imperfection case. These peak strains are centerline strains in the respective plates. (The remaining columns of Tables 2-4 are used in Section 4.)

Table 4. Peak mid-thickness $\mu$ strain at $69 \mathrm{kN}$. SK and ST denote skin and stiffener, respectively. * Peak strain is given at $65.5 \mathrm{kN}$

\begin{tabular}{cccc}
\hline $\begin{array}{c}\text { Software: } \\
\text { (Model:) }\end{array}$ & VICONOPT & $\begin{array}{c}\text { ABAQUS } \\
\text { (V’OPT) }\end{array}$ & $\begin{array}{c}\text { ABAQUS } \\
(\mathrm{expt})\end{array}$ \\
\hline 0 & - & $-2963(\mathrm{SK})$ & $-3565(\mathrm{SK})$ \\
$-l / 500$ & $-3000(\mathrm{ST})$ & $-2676(\mathrm{SK})$ & $-2692(\mathrm{SK})$ \\
$+l / 500$ & $-2340(\mathrm{SK})$ & $-3891(\mathrm{SK})$ & $-5665(\mathrm{SK})^{*}$ \\
\hline \hline
\end{tabular}

\subsection{Design Histories}

Figures 2-4 show the design history of the panel. Their abscissae indicate the number of design cycles completed, with 0 denoting the initial design. Twenty design cycles were performed but the converged design was reached after 16. These Figures show variations that are significant early on in the design process but which reduce as convergence is approached.

Figure 2 shows the mass and initial buckling load histories. The buckling loads (see the right hand

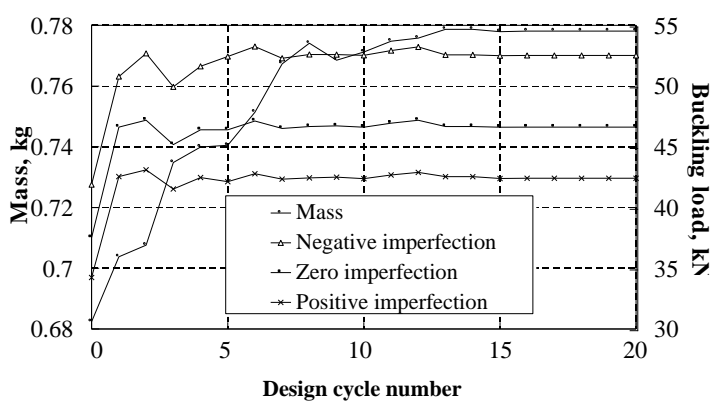

Fig. 2. Mass history and initial buckling load history for negative, zero and positive imperfections.

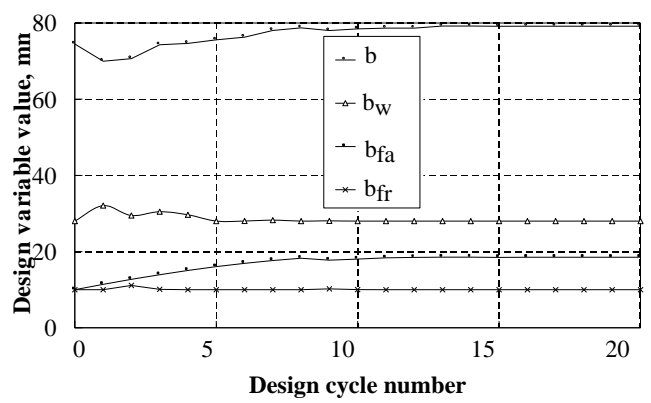

Fig. 3. Design variable history for panel.

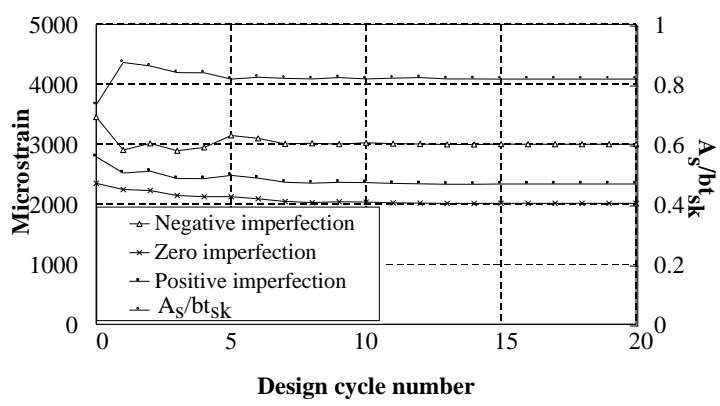

Fig. 4. Peak compressive strain histories for negative, zero and positive imperfections and $\mathrm{A}_{\mathrm{s}} / \mathrm{bt}_{\mathrm{sk}}$ history.

scale) for each of the intermediate cycles are for full stiffness properties in all the plates so that their stress distribution is even. The buckling load converges faster than mass does, because other constraints are not being satisfied.

Figure 3 shows the design variable history of the panel. The width of the attached flange, $b_{\text {fa }}$, increases substantially, from $10 \mathrm{~mm}$ to $18.5 \mathrm{~mm}$, causing a substantial increase of the local stiffness around the base of the stiffener.

Figure 4 shows the strain and $\mathrm{A}_{\mathrm{s}} / \mathrm{bt}_{\mathrm{sk}}$ histories of the panel during the design process. The peak strain was kept below the allowable limit of $3600 \mu$ strain throughout the design. The final design violates the intended constraint $\mathrm{A}_{\mathrm{s}} / \mathrm{bt}_{\mathrm{sk}} \leq 0.8$ despite the program having tried to satisfy it. This violation is due to the problem being over-constrained, because the nature and number of the active design constraints prevents 
them from being simultaneously satisfied by variation of the small number of design variables used. Strictly, this makes the design problem an insoluble one and a practical consequence was that different constraints were violated and to different extents, depending upon the starting design chosen. For some starting designs there was a significant failure to achieve the design load. Hence a number of different design runs were made and judgement was used to pick the constrained design given in Table 1 from among these, the principal criterion being that the failure load should be very close (it was $68.3 \mathrm{kN}$ versus $69 \mathrm{kN}$ ) to the design load. The over-constrained nature of the problem and the need to omit stabilization made it a very demanding test of VICONOPT despite its superficially appearing to be a relatively simple problem.

\section{Finite Element Modeling and Results}

Finite element (FE) modeling was carried out to determine both the bifurcation buckling and the postbuckling behavior of the panel, using the package ABAQUS. ${ }^{8}$ The purpose was both to validate the VICONOPT design and to predict the failure of an actual panel in the laboratory. Since slightly different boundary conditions were applied in VICONOPT compared with those applied in the laboratory, two FE models were developed. The first, denoted ABAQUS(V'OPT), matches as closely as possible the assumptions applied within VICONOPT, whilst the second, denoted ABAQUS(expt), matches the test conditions used in the laboratory.

The models used 10160 Quad 4 thin shell elements. The end conditions and load distributions used in each model were applied using a combination of degree of freedom constraints, multi-point constraints and loads. In both cases the panel ends were simply supported, but in the ABAQUS (V'OPT) model, the upper flanges of the stiffeners were also allowed to warp in their plane to match the VICONOPT end conditions as closely as possible. In both FE models load was always applied along the neutral axis of the unbuckled panel, resulting in an initially uniform axial strain when no imperfection was present.

Table 5. Measured material properties for $\mathrm{Al} 6082$ T6 used in the skin (SK) and stiffeners (ST).

\begin{tabular}{c|ccccccc}
\hline \hline & $\mu$ strain & 0 & 2000 & 3000 & 4000 & 5000 & 6000 \\
\hline \multirow{3}{*}{ SK } & $\sigma, \mathrm{MPa}$ & 0 & 156 & 223 & 277 & 299 & 309 \\
& $\mathrm{E}, \mathrm{GPa}$ & 76.1 & 72.5 & 66.6 & 36.4 & 12.8 & 6.4 \\
\hline \multirow{2}{*}{ ST } & $\sigma, \mathrm{MPa}$ & 0 & 154 & 220 & 266 & 286 & 294 \\
& $\mathrm{E}, \mathrm{GPa}$ & 71.6 & 69.5 & 60.8 & 26.5 & 12.4 & 4.4 \\
\hline \hline
\end{tabular}

In the ABAQUS(V'OPT) model the shell elements were assumed to behave in a purely elastic manner with the values of $\mathrm{E}, v$ and thickness given in Section 3.1.

The effect of material plasticity was included in the ABAQUS(expt) model using the material properties given in Table 5 and $v=0.33$. These properties were obtained from a series of tensile tests on samples of the material. In the ABAQUS(expt) model the actual thicknesses of $0.988 \mathrm{~mm}$ and $1.17 \mathrm{~mm}$ were used for the skin and stiffener, respectively.

Table 2 shows that there is reasonable agreement between the lowest three bifurcation buckling modes given by ABAQUS and those given by VICONOPT. As might be expected, the ABAQUS(V'OPT) model gives the best agreement with the VICONOPT results. The ABAQUS(expt) model solutions are lower, due to the reduced thickness of the actual material and the change in E. (This was confirmed by modifying the model using the ideal material thicknesses and an elastic modulus of $72.4 \mathrm{GPa}$. Here the lowest ABAQUS(expt) solution was also $45.9 \mathrm{kN}$.) All the buckling modes are skin modes, but the ABAQUS results consistently have one fewer half-wavelength in their buckled shape than the VICONOPT results, for the modes shown, probably because of the small differences in boundary conditions.

Table 3 compares the non-linear solutions found using ABAQUS and VICONOPT and Figs. 5 and 6 show typical end shortening plots, using the ABAQUS(V'OPT) and the ABAQUS(expt) models for the perfect panel case. A typical final deformed shape is also shown in Fig. 6. Unless otherwise stated in Table 3 the local buckling load has been given as the average of the load at the beginning and end of the analysis step where negative eigenvalues first appear in the non-linear solution.

From Table 3 it can be seen that the local buckling loads given by VICONOPT and both the ABAQUS non-linear solutions are similar for all imperfections. Again, whilst VICONOPT always

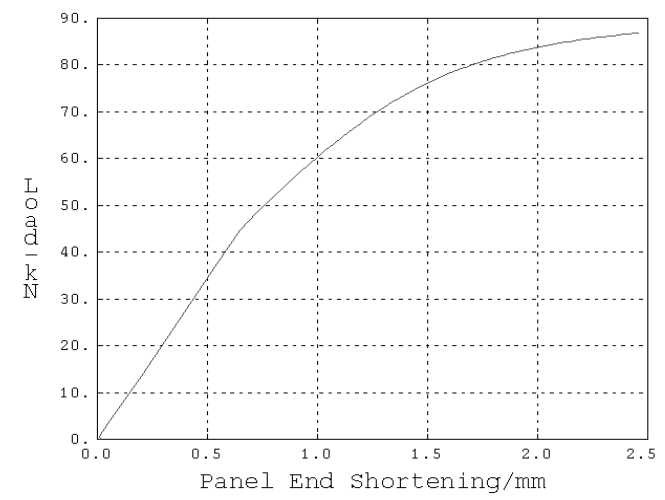

Fig 5. End-shortening plot given by the ABAQUS(V'OPT) model, for a perfect panel. 
predicts that the local buckled shape should be a skin mode with a half-wavelength of $l / 10$, the ABAQUS model always predicts a skin mode with a halfwavelength of $l / 9$, see Fig. 6 .

Both elastic solutions give post-buckled solutions that indicate that the panel will behave in a stable manner up to and beyond the design load of $69 \mathrm{kN}$, but there are significant differences between the solutions. ABAQUS, as shown in Fig. 5, predicts that the panel will exhibit a stable skin mode to loads well in excess of the design load. Indeed, no ultimate failure load was found in any of the ABAQUS (V'OPT) model solutions before they were terminated. Conversely VICONOPT, for the reasons given in Section 3, could only predict that the panel would not fail below the design load. In addition, the solution given by VICONOPT indicates that for the $-l / 500$ case the panel may fail due to an interaction with a torsional mode of half-wavelength $l / 2$.

Whilst both elastic solutions predicted that the panel design was acceptable in all cases, the ABAQUS (expt) model solution predicts that for the $+l / 500$ case the panel will not quite be able to support the design load. This is due to the effects of plasticity, see below. However, for both the negative and zero imperfection cases the ABAQUS(expt) model predicts that the panel will satisfy the design load requirement. For all FE solutions the predicted failure mode is an interaction between a skin mode with 9 half-wavelengths and an overall mode. Note that the
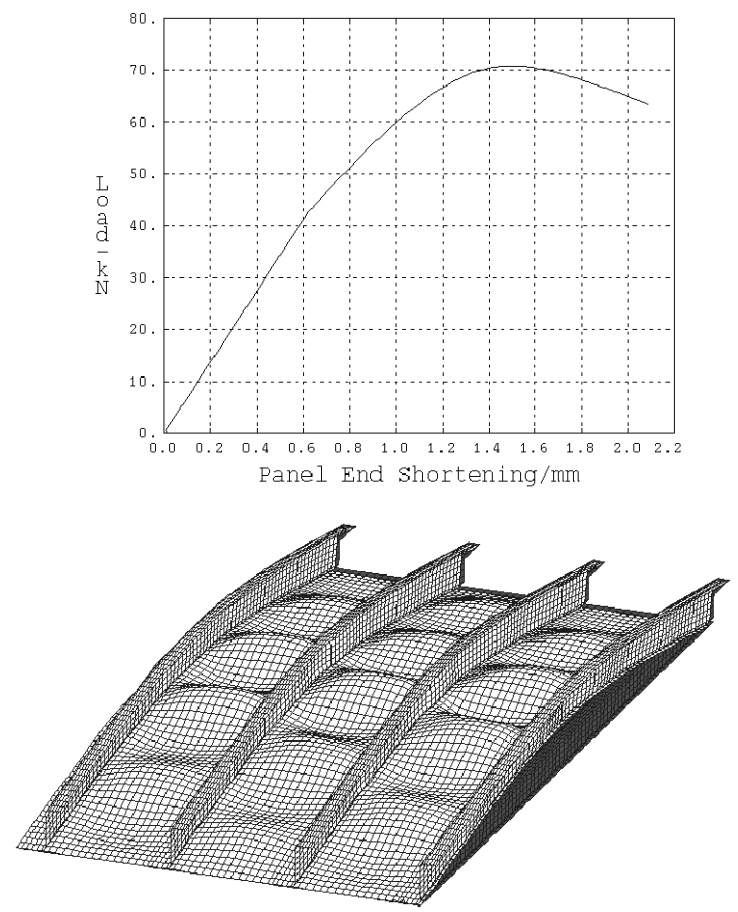

Fig. 6 End-shortening plot and final deformed shape given by the ABAQUS(expt) model for a perfect panel. reduction in the initial buckling and failure loads due to the material thicknesses used in the experimental model being slightly lower than the ideal values used in the elastic models is unknown.

The ABAQUS peak strains are given in Table 4 and all occur in the skin, next to the stiffener, on the side opposite the lower flange. (Note. Negative strain is compressive.) For the $-l / 500$ case VICONOPT has the highest peak strain, predicting it will occur in the upper flange of the stiffener, whilst both ABAQUS models predict that the highest peak strain will occur at a value $11 \%$ lower. For the ABAQUS (V'OPT) model, the highest peak strain for the $+l / 500$ case is about $66 \%$ higher than the VICONOPT solution. This level of strain is close to the point were the material starts to behave plastically. This explains why in the ABAQUS(expt) solution for the $+l / 500$ case the panel fails at a load of $65.5 \mathrm{kN}$, at which the peak strain is well into the region where the material behaves plastically. The differences in the solutions are due to differences in loading in the post-buckled regime in VICONOPT and ABAQUS models and will be discussed fully in Section 6.

\section{$\underline{\text { 5. Experimental Testing and Results }}$}

Four panels were manufactured to the constrained design of Table 1, produced by VICONOPT. Their stiffeners were attached to the skin using adhesive plus rivets that were placed at $25 \mathrm{~mm}$ spacing along the middle of the stiffener lower flanges, both to position the stiffeners during curing and also to provide some extra strength in the joint. Once the stiffeners had been attached, the panel ends were machined to ensure that they were flush.

The experimental methodology has previously been used successfully. ${ }^{13}$ For the current set of tests, strains before and after initial buckling were recorded using strain gauges attached across the mid-length of the panel to each stiffener upper flange, the middle of each skin section and to the lower web of the two central stiffeners. The recorded strains were compared to pre-buckling predictions of strain in the panel, in order to both monitor the test imperfections, ensuring that they were within acceptable limits, and also to help determine the onset and advance of buckling. For brevity only a representative sample of the strain data will be presented.

Table 6 compares the experimental results obtained during the laboratory tests with the predictions given by VICONOPT and ABAQUS. There is good agreement between the predicted and experimental failure loads. All the panels failed at loads greater than the design load despite the initial imperfection being in the weaker positive direction for tests A-C. The cause of failure for two 
Table 6. Experimental results and theoretical predictions. (All loads in $\mathrm{kN}$ )

\begin{tabular}{c|cccc|cc|cc}
\hline \hline & \multicolumn{4}{|c|}{ Experimental test } & \multicolumn{2}{c|}{ VICONOPT } & \multicolumn{2}{c}{ ABAQUS } \\
Test & $\mathrm{A}$ & $\mathrm{B}$ & $\mathrm{C}$ & $\mathrm{D}$ & & \multicolumn{2}{c}{$(\mathrm{expt})$} \\
\hline Initial imperfection & $+\mathrm{ve}$ & $+\mathrm{ve}$ & $+\mathrm{ve}$ & $-\mathrm{ve}$ & $-l / 500$ & $l / 500$ & $-l / 500$ & $l / 500$ \\
Local buckling load & $37.0(l / 9)$ & $37.0(l / 9)$ & $41.0(l / 9)$ & $46.0(l / 9)$ & $52.5(l / 10)$ & $42.4(l / 10)$ & $45.9(l / 9)$ & $39.1(l / 9)$ \\
Failure load & $72.0(l / 9)$ & $71.6(l / 9)$ & $74.0(l / 9)$ & $77.0(l / 9)$ & $>71.3(l / 2)$ & $>68.3(l / 9)$ & $78.8(l / 9)$ & $65.4(l / 9)$ \\
\hline \hline
\end{tabular}

experiments differs from that predicted by theoretical methods. ABAQUS predicted that in every case, failure is due to an interaction between the initial skin mode and an overall mode. In tests A and B failure was due to a local buckle in the lower flange/skin interface at the free panel edge, see Fig. 7. Some plastic deformation in the skin sections also occurred across the panel, originating from the large plastic deformation at the panel edge. In tests $\mathrm{C}$ and $\mathrm{D}$, see Fig. 7, the predicted type of failure occurred. In every case the panel retained the ability to carry load after failure, although the load drop-off varied between $14 \%$ of the failure load for the test A and $68 \%$ for test D.

The local buckling loads were assumed to occur when the strain-load relationship ceased to be linear. In Fig. 8, which shows the strain at the mid-breath of the central skin section during test $\mathrm{B}$, this point can clearly be seen. Here, SK2 is the strain gauge attached to the surface of the central skin section at the panel mid-length, on the side of the stiffeners, whilst SK2R is the strain gauge directly opposite on the other side of the skin and is visible in the Test B photograph of Fig. 7. Figure 9 shows the similarity in ABAQUS prediction of strain at this point in the skin but indicates initial local buckling in the opposite sense to the experimental data given in Fig. 8. This difference is a consequence of the multiple equilibrium states following bifurcation buckling.

The local buckling loads of the first two panel tests were about $5.4 \%$ below the lowest value

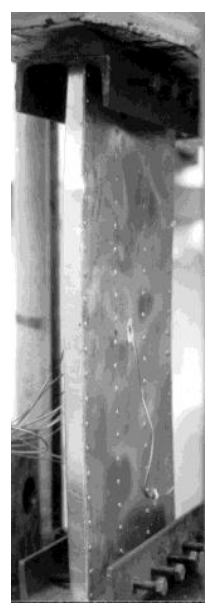

Test A

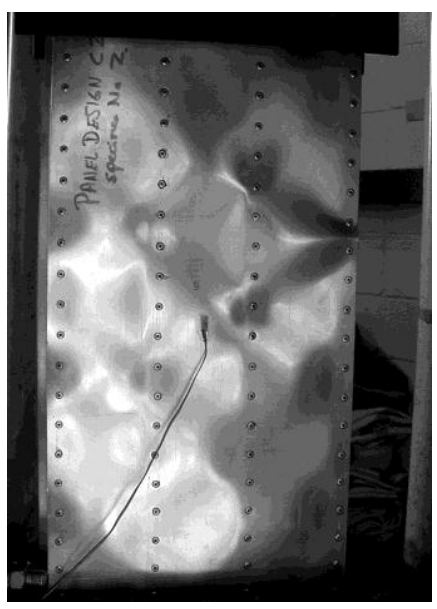

Test B

predicted by the ABAQUS(expt) model, whilst the loads given by tests $\mathrm{C}$ and $\mathrm{D}$ were within the range of the predicted values for this model. The local buckling load for test $\mathrm{D}$ was the highest due to the negative initial imperfection. The differences between the values given for tests $\mathrm{A}, \mathrm{B}$ and $\mathrm{C}$ may partly be due to the fact that the stiffeners in test $\mathrm{C}$ were made from a different sheet of Al6082-T6 from that used for the stiffeners for tests $\mathrm{A}$ and $\mathrm{B}$, and also that the initial imperfection was bigger in tests $\mathrm{A}$ and $\mathrm{B}$. In all the laboratory tests the panels initially buckled in the skin, in 9 half-wavelengths, and remained buckled in this state until failure. Whilst this matches the ABAQUS buckled shape predictions, for the $+l / 500$ case, VICONOPT predicted that local buckling would be in 10 half-wavelengths, although it did predict an interaction with a 9 half-wavelength mode at failure.

All the panels seemed to remain buckled in 9 halfwavelengths during the post-buckled regime. However, there is evidence in the strain data taken during test $\mathrm{A}$ to suggest that a change in the buckling pattern occurred. It is thought that the length of each half-wavelength was not uniform along the panel and changed as load was applied.

\section{Discussion}

As can be seen from the results given above, both theoretical methods predicted that the panel would initially buckle in the skin and then behave in a stable manner in the post-buckled regime until the design load. This behavior was confirmed by the tests carried out in the laboratory.

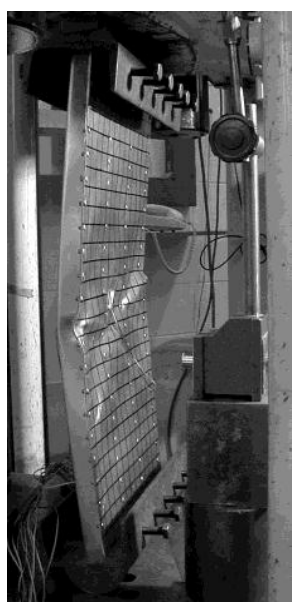

Test C

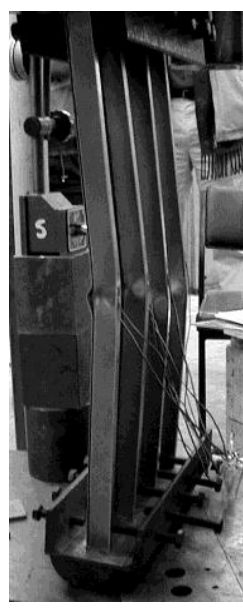

Test D

Fig. 7. Panel failure modes. In tests A and B panel failures are due to local buckling at the panel edge, whilst in tests $\mathrm{C}$ and $\mathrm{D}$ failures are due to interaction between skin and overall modes. 


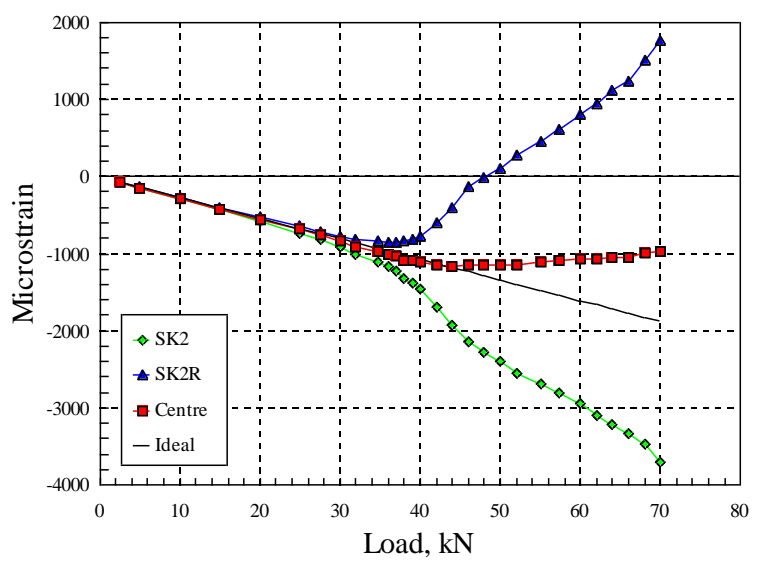

Fig. 8. Strain at the mid-length of the central skin section during test $\mathrm{B}$.

Whilst both theoretical methods correctly predicted that the panel would approximately satisfy the design load requirement there are significant differences in the results predicted by VICONOPT and those predicted by ABAQUS and also those obtained in the laboratory, particularly in the region beyond the local buckling load. These differences can be explained by a number of reasons.

Firstly, the solution obtained by VICONOPT is not the result of a fully non-linear analysis, but of a bifurcation analysis of the panel in its assumed buckled state. Thus the VICONOPT solution simply indicates that there are no buckling loads below the design load for the skin-buckled panel, and therefore no possibility of failure below the design load.

The second reason for the differences is that the load distributions in the ABAQUS models and the experiment do not match that used by VICONOPT in the post-buckling regime. In all cases the panel is initially loaded along its unbuckled neutral axis. When the skin buckles the neutral axis will move away from the skin. In the VICONOPT model the load follows this shift in the neutral axis position, which may well match the boundary conditions in a compression panel of an aircraft wing subject to overall bending moment. In the ABAQUS models and in the experiment, the load position remains fixed, so that in the post-buckled regime there is an offset between the load and the neutral axis. This results in an out-of-plane bending moment, which exaggerates the skin buckling.

The effect of this out-of-plane bending moment can clearly be seen in Fig. 10 which is a bifurcation plot giving a schematic representation of the initial post-buckled behavior of the panel. The amplitude plotted on the horizontal axis is the out-of-plane

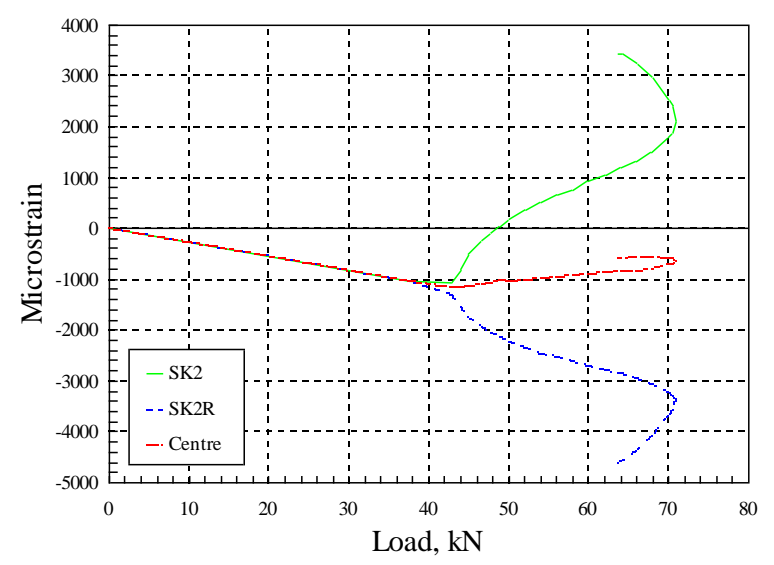

Fig. 9. Theoretical strain at the mid-length of the central skin section for a perfect panel.

displacement of the panel at its mid-point, where positive (negative) amplitude increases (decreases) compression in the skin and decreases (increases) compression in the stiffeners.

During the initial loading of the panel, all the analysis methods and the experiment assume that the panel is loaded along its initial neutral axis, hence curve 1 is common to all solutions. Once local skin buckling occurs, the behaviors predicted by the theoretical methods diverge, due to deviation in the out-of-plane bending moment. The behavior obtained in the laboratory follows that predicted by ABAQUS. The VICONOPT solutions continue to diverge in the same direction but at a greater rate than curve 1 , following curve 2 on Fig. 10. The ABAQUS solutions and the experiment follow the behavior given by curve 3 . These, due to the out-of-plane moment have a more positive amplitude at a given load compared to the curve produced by the VICONOPT assumptions. Indeed the effect is most noticeable in the negative initial imperfection case, where the amplitude increase reverses direction so that both solutions, once the load is great enough, have positive out-of-plane displacements. For the out-of-plane displacement of the negative case to remain negative the initial imperfection would have to be excessively large. From the bifurcation plot it can be seen that for a initial positive imperfection the solution given by ABAQUS is conservative, whilst for the initial negative imperfection the solution given by VICONOPT is likely to be conservative.

The bifurcation plot assumes that the material behaves elastically throughout the analysis. If plasticity is included its effect would be to increase the out-of-plane displacement at a given load, once the material starts to behave in a plastic manner, and hence would result in the local buckling and failure loads occurring earlier. 


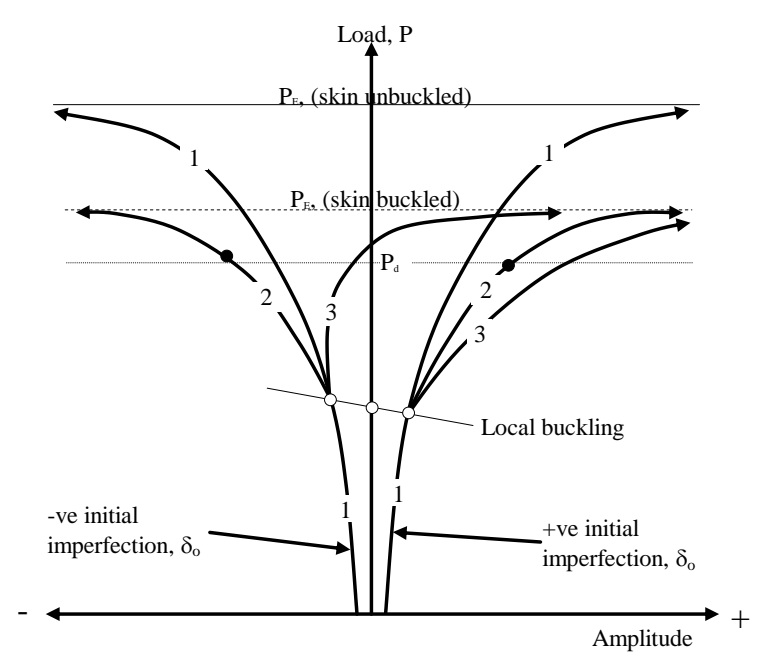

Fig. 10. Schematic representation of loadamplitude relationship for initial (pre-buckling) panel (curve 1) and post-buckled panel for VICONOPT assumptions (curve 2) and ABAQUS assumptions/experiment (curve 3). $\mathrm{P}_{\mathrm{E}}$ is the Euler load of the panel and $\mathrm{P}_{\mathrm{d}}$ is the design load of the panel. The hollow circles denote local skin buckling loads and the solid circles denote the VICONOPT post-buckled solutions.

The loading difference also accounts for the difference in the failure modes predicted by ABAQUS and found in the experiments, where failure always occurs due to an interaction between local skin and overall modes, and VICONOPT, which predicts that for the $-l / 500$ case, failure will be as a result of an interaction with a torsional stiffener mode. This difference also accounts for the fact that VICONOPT predicts the largest peak strain for the $-l / 500$ case and that it will occur in the upper stiffener flange, whilst ABAQUS always predicts that the maximum strain occurs in the skin. As can be seen in Fig. 10, the out-of-plane displacement at the design load of the ABAQUS models is significantly less than that of the VICONOPT model. Thus there is a smaller end effective moment resulting in a smaller strain in the ABAQUS models. Conversely, for the $+l / 500$ case the out of plane displacement is larger for the ABAQUS models, giving a bigger effective end moment and thus increasing the strain due to bending in the skin. One additional cause of the differing strain values predicted by ABAQUS and VICONOPT is that VICONOPT only gives an average of peak strain in the skin or upper flange, whilst ABAQUS takes into account the change in strain distribution caused by the actual post-buckled shape of the panel.

\section{Conclusions}

The local buckling loads, failure loads and buckled mode shapes given by the plastic ABAQUS model match well the behavior of the panel in the laboratory. Furthermore, the failure loads obtained using ABAQUS with non-linear material behavior and the experimental failure loads coincide quite well with the predicted VICONOPT design loads. Considering the differences in assumptions of the two computer programs, this may appear to be somewhat coincidental. However, the more severe failure criterion in VICONOPT seems to offset its reduced out-of-plane bending moment following buckling. Hence for an overall imperfection which increases compression in the skin the VICONOPT solution could be considered to be well designed. However, VICONOPT predicts an unstable stiffener failure mode for an imperfection that increases compression in the stiffeners. Due to the loading differences in the two programs this prediction cannot be confirmed by either the ABAQUS solutions or by the experiment. Neither of the solutions given by VICONOPT and ABAQUS completely matches the boundary conditions found in a real aircraft compression panel, although the boundary conditions and loading distribution of VICONOPT are possibly the closer of the two.

Overall, the ABAQUS and experimental results suggest that VICONOPT can give satisfactory preliminary designs, even when the design is overconstrained.

Acknowledgements

The authors wish to thank the Engineering and Physical Sciences Research Council (GR/M26220 and GR/M26237) and BAE Systems, Airbus for providing the financial assistance that made this work possible. In addition they would like to thank Dr. M.S. Anderson for the helpful comments he has made.

1. Hutchinson, J.W., and Koiter, W.T., "Postbuckling theory," Applied Mechanics Reviews, Vol. 23, 1970, pp. 1353-1366.

2. Bushnell, D., "Optimization of Composite, Stiffened, Imperfect Panels Under Combined Loads for Service in the Postbuckling Regime," Computer Methods in Applied Mechanics and Engineering, Vol. 103, 1993, pp. 43-114.

3. Anderson, M.S., "Design of Panels Having Postbuckling Strength," Proceedings of 38th AIAA/ASME/ASCE/AHS/ASC Structures, Structural Dynamics, and Materials Conference, Kissimme, FL, 1997, pp. 2407-2413.

4. Bushnell, D., Rankin, C.C., and Riks, E., "Optimization of Stiffened Panels in Which Mode Jumping is Accounted For," Proceedings of 38th AIAA/ASME/ ASCE/AHS/ASC Structures, Structural Dynamics, and Materials Conference, 1997, pp. 2123-2162.

5. Everall, P.R., and Hunt, G.W., "Arnold Tongue Predictions of Secondary Buckling in Thin Elastic 
Plates," Journal of the Mechanics and Physics of Solids, Vol. 476, 1999, pp. 2187-2206.

6. Hunt, G.W., "An Algorithm for the Non-linear Analysis of Compound Branching," Philosophical Transactions of the Royal Society of London., Vol. A300, No. 1455, 1981, pp. 443-471.

7. Butler, R., and Williams, F. W., "Optimum Design Using VICONOPT, a Buckling and Strength Constraint Program for Prismatic Assemblies of Anisotropic Plates," Computers and Structures, Vol. 43, 1992, pp. 699-708.

8. Hibbitt, Karlsson, and Sorensen, Inc., “ABAQUS/Standard User's Manual," Version 5.7, Pawtucket, RI, 1997.

9. Wittrick, W.H., and Williams, F.W., "A General Algorithm for Computing Natural Frequencies of Elastic Structures," Quarterly Journal of Mechanics and Applied Mathematics, Vol. 24, 1971, pp. $263-$ 284.

10. Wittrick, W. H., and Williams, F. W., "Buckling and Vibration of Anisotropic or Isotropic Plate Assemblies Under Combined Loadings," International Journal of Mechanical Sciences, Vol. 16, 1974, pp. 209-239.

11. Anderson, M. S., Williams, F. W., and Wright, C. J., "Buckling and Vibration of Any Prismatic Assembly of Shear and Compression Loaded Anisotropic Plates with an Arbitrary Supporting Structure," International Journal of Mechanical Sciences, Vol. 25, 1983, pp. 585-596.

12. Powell, S.M, Williams, F.W, Askar, A.-S., and Kennedy, D., "Local Postbuckling Analysis for Perfect and Imperfect Longitudinally Compressed Plates and Panels," Proceedings of the 39th AIAA/ASME/ASCE/AHS/ASC Structures, Structural Dynamics and Materials Conference, Long Beach, CA, 1998, pp. 595-603.

13. Butler, R., Lillico, M., Hunt, G.W., and McDonald, N.J., "Experiments on Interactive Buckling in Optimized Stiffened Panels," Proceedings of the $1^{\text {st }}$ ASMO UK/ISSMO Conference on Engineering Design Optimization, Ilkley, U.K., 1999, pp. 89-96. 